\title{
Contraceptive use among women in Ogoja and Obudu Local Government Areas, Cross River State, Nigeria'
}

\author{
David B. Ugal, PhD \\ Department of Social Studies, Federal College of Education, Obudu,Nigeria \\ daveugal@yahoo.com
}

Boniface A. Ushie, PhD

Institute of Child Health, College of Medicine, University of Ibadan, Nigeria

\begin{abstract}
Sexual behaviour in human societies is embedded in a complex web of shared ideas. Moral rules and regulations, obvious associations and obscured symbols are part of the complex behaviour patterns. Sexual behaviour varies from one culture to another, from one stage of development to another as well as from one period of history to another. Many factors including biological, social, political, educational, economic and religious affect sexual behaviour. This study was undertaken to assess women's knowledge of modern contraception, examine the role of culture in contraception use and find out the relationship between background characteristics and contraception use. The results of this study indicate that knowledge of contraception is relatively low in both rural and urban centres of the study area. Given the importance of family planning to the reduction of growing population, it is crucial to embark on an aggressive education and enlightenment of the people on the need to use contraception in order to prevent unwanted, unintended and ill-timed pregnancies. The media should be effectively harnessed to take its rightful position in the dissemination of information to the people.
\end{abstract}

Key words: Knowledge, contraceptive, use, Obudu, Ogoja

\section{Résumé}

Le comportement sexuel dans les sociétés humaines est intégré dans un réseau complexe d'idées partagées. Les règles morales et des règlements, des associations et des symboles évidents occultés font partie des comportements complexes. Le comportement sexuel varie d'une culture à l'autre, d'un stade de développement à un autre ainsi que d'une période de l'histoire à l'autre. De nombreux facteurs, notamment biologique, social, politique, éducatif, économique et religieux influent sur le comportement sexuel. Cette étude a été menée afin d'évaluer les connaissances des femmes modernes de contraception, d'examiner le rôle de la culture dans l'utilisation de la contraception et découvrir la relation entre les caractéristiques de base et l'utilisation de la contraception. Les résultats de cette étude indiquent que la connaissance de la contraception est relativement faible dans les centres ruraux et urbains de la zone d'étude. Compte tenu de l'importance de la planification familiale à la réduction de la croissance démographique, il est crucial de se lancer dans une dynamique d'éducation et l'éveil de la population sur la nécessité de recourir à la contraception pour éviter les grossesses non désirées, imprévu et inopportun. Les médias doivent être efficacement mises à profit pour prendre sa place légitime dans la diffusion de l'information à la population.

Mots clés: la connaissance. contraceptive, l'utilisation, Obudu, Ogoja

\section{Introduction}

Sexual behaviour in human societies is embedded in a complex web of shared ideas. Moral rules and regulations, obvious associations and obscured symbols are part of the complex behaviour patterns. Sexual behaviour varies from one culture to another, from one stage of development to another as well as from one period of history to another. Many factors, including biological, social, political, educational, economic and religious affect sexual behaviour. Nigeria is the most populous country in Africa, with more than 167 million people with a high annual population growth rate $(4.5 \%)$ and a

I. This paper is part of a study sponsored by the Educational Trust Fund. 
total fertility rate of 5.4 lifetime births per woman. Additionally, the country has relatively high levels of infant mortality (104 infant deaths per 1,000 live births) and maternal mortality (800 maternal deaths per 100,000 live births). In response to these and other serious demographic and health issues, the Nigerian government put into effect a national population policy in 1989 and reviewed in 2004, which called for a reduction in the birth rate through voluntary fertility regulation methods compatible with the nation's economic and social goals.

Despite high birth rates in most of Nigeria, government population and development policies stress economic development rather than attempts to reduce fertility. The contraceptive information and services offered to single women in most developing countries is compromised by stigma attached to premarital sex (Ozumba et al. 2005). Oye-Adeniran et al. (2004) indicated that large numbers of Nigerian women experience unwanted or mistimed pregnancies and births. According to a 1997 survey of women in south-western Nigeria, at least $27 \%$ of women had ever been pregnant when they did not want to be. Similarly, in a survey conducted in south-western and northern Nigeria in the mid-1990s, $20 \%$ of women reported ever having experienced an unwanted pregnancy (Okonofua et al., 1999). The 2003 Demographic and Health Survey (DHS) found that of all live births to women in the previous three years, $15 \%$ were reported to be unplanned. It has been estimated that about $12 \%$ of all pregnancies in Nigeria (not including those that result in spontaneous abortion) end in induced abortion, and another $9 \%$ result in unplanned births (Henshaw et al., 1998).

Unintended pregnancy poses significant public health risks. One consequence of unwanted pregnancy is induced abortion. In the mid1990s, the abortion rate in Nigeria was estimated at 25 per 1,000 women. At this rate, approximately 760,000 abortions would have occurred in 2006. Because abortion is illegal in Nigeria except to save a woman's life, many procedures are conducted under unsafe conditions and carry a substantial risk of maternal morbidity and mortality (Makinwa-Adebusoye et al., 1997). It is estimated that about $25 \%$ of women who have abortions in Nigeria experience serious complications (Oye-Adeniran et al.
2004). According to national surveys, Nigerian women and couples want fewer children than they once did: between 1990 and 2003, the mean desired number of children declined from 5.8 to 5.3 (Bankole et al. 2006). Even so, levels of contraceptive use remain low: in 2003, only $7 \%$ of married women used a modern contraceptive method and another $6 \%$ relied on a traditional or folk method (Hussain et al. 2005). The combination of low contraceptive use and smaller desired family size implies high levels of unmet need for family planning in Nigeria. Indeed, among married women of reproductive age, $32 \%$ do not want to have a child in the near future but are not using a modern contraceptive method, and are therefore at risk of an unwanted pregnancy (Hussain et al., 2005).

Research on reasons for non-use of family planning in Nigeria generally points to women's perceived lack of need for contraception, fear of side effects and opposition to contraception on personal or religious grounds [National Population Commission (NPC), 2004]. The limited evidence available from small studies in various parts of Nigeria generally points to reasons such as the need to space births, economic constraints, the desire to remain in school and not being married (Oye-Adeniran et al. 2004).

Several studies have reported changes in Nigerians' knowledge of, and attitudes toward, family planning. Yet, the majority of women do not use any modern family planning method even when they have achieved their desired number of children or when they are not prepared for pregnancy. While we know that nonuse results in unplanned pregnancies and that a small proportion of women use any form of contraceptives, it is important to locate the reasons for non-use in this particular locale, which has high rates of children per family. Thus, the purpose of this study is to examine contraceptives use among women 15-49 years old in Obudu and Ogoja Local Government Areas (LGAs), Cross River State, Nigeria.

\section{Data and methods}

The study was conducted in two LGAs, Obudu and Ogoja, which are in the Northern senatorial district of Cross River State, Nigeria. This region is made up of five LGAs but these two are the oldest from which the remaining three were 
created. Hence, these were purposively selected for the study. The characteristics in all these LGAs are therefore found in these two. Ogoja LGA used to be the headquarters of old Ogoja province. It has the features of an urban society as a result of this, while Obudu is the next oldest LGA in the Northern Cross River State.

Data for this study derived from a community-based, cross-sectional survey of women conducted in 2007-2008 among I,424 women aged I5-49 years. The most urban LGA and the most rural areas in each of the health zones were chosen; the researchers used the ruralurban distribution of women in the 1999 Nigeria DHS to make these determinations. From each LGA, we used the town where the secretariat is located as the urban in addition to 10 rural communities. Within each of the rural communities, 36 women were randomly selected through canvassing of all households. In the urban areas, I 0 enumeration areas were randomly selected, and within each enumeration area, 36 households and 36 eligible women were selected for interview. However, after cleaning, incomplete questionnaire were excluded, thus, the total number of participants included in the analysis were 1,085 . Prior to administering the instruments, the research protocol - including the study design, questionnaire, informed consent procedure and means of preserving respondents' confidentiality - was reviewed and approved by the state Ministry of Health Ethical Committee.

Data were collected on respondents' social, economic and demographic characteristics. To measure women's socio-economic status, a series of questions about household assets and wealth were asked. Using the same approach as the DHS, a wealth index was constructed using variables indicating the level of wealth in each woman's household. The women were asked which item, from a list of nearly 20 material goods (e.g., radio, television, refrigerator and car) they had in households. A composite score computed from the list of household material items was used to classify respondents into the low, middle and high socioeconomic status. In addition, participants were asked about their pregnancy and fertility behaviours and preferences, contraceptive use history and sexual activity. We also obtained information on the numbers of pregnancies and live births, and their knowledge of and experience with contraception.

Univariate, bivariate and multivariate logistic regression analyses were performed to determine the prevalence of unwanted pregnancy and the factors associated with their outcome. All estimates were weighted. Data entry and analyses were carried out using the Statistical Package for Social Sciences (SPSS) version 15.

\section{Results}

Table I displays the socio-demographic characteristics of respondents in the study. A middle heavy age structure was observed in areas with more women $(24.5 \%)$ in the $25-29$ age group while the least was those aged 45-49 years where, expectedly, reproductive activities declines. A majority (68.4\%) of respondents were married while $7.6 \%$ were separated. This is within the framework of the assertion that child birth takes place in wedlock. Almost all (97.2\%) the respondents were Christians with $74.7 \%$ being Catholics. This indicates that inhabitants of the study area are predominantly Christian, with implications for contraceptive knowledge and use. The respondents are predominantly educated, with $79.9 \%$ having at least a secondary education. It is instructive that they are likely be change agents in matters relating to contraception.

Respondents were employed in various occupations that require some educational training with civil servants as the most. The majority $(61.6 \%)$ of the respondents did not indicate their income, but among those who did, $19.6 \%$ earned just about 10,000 naira or less.

A substantial percentage of respondents started giving birth quite early with $26.9 \%$ already giving birth before their $20^{\text {th }}$ birth day. The knowledge of contraception must be crucial to help those who have debut sexual activity to prevent unwanted and unintended pregnancies. 
Table I Distribution of respondents by selected socio-demographic characteristics

\begin{tabular}{|c|c|c|}
\hline Selected socio-demographics & $\begin{array}{l}\text { Frequency } N \\
=1,085\end{array}$ & Percent $=100.0$ \\
\hline \multicolumn{3}{|l|}{ Age Group } \\
\hline $15-19$ & 85 & 7.8 \\
\hline $20-24$ & 203 & 18.7 \\
\hline $25-29$ & 266 & 24.5 \\
\hline 30-34 & 213 & 19.6 \\
\hline $35-39$ & 147 & 13.5 \\
\hline $40-44$ & 116 & 10.7 \\
\hline $45-49$ & 55 & 5.1 \\
\hline \multicolumn{3}{|l|}{ Marital status } \\
\hline Single & 261 & 24.1 \\
\hline Married/Cohabiting & 742 & 68.4 \\
\hline Separated/Divorce/widowed & 82 & 7.6 \\
\hline \multicolumn{3}{|l|}{ Religious affiliations } \\
\hline Catholic & 811 & 74.7 \\
\hline Protestant & 243 & 22.4 \\
\hline Muslim & 23 & 2.1 \\
\hline Traditional & 8 & .7 \\
\hline \multicolumn{3}{|l|}{ Educational qualification } \\
\hline No formal school & 72 & 6.6 \\
\hline Primary & 146 & 13.5 \\
\hline Secondary & 410 & 37.8 \\
\hline Degree & 457 & 42.1 \\
\hline \multicolumn{3}{|l|}{ Monthly income } \\
\hline 10,000 & 881 & 81.2 \\
\hline $11,000-20,000$ & 97 & 8.9 \\
\hline $21,000-30,000$ & 52 & 4.8 \\
\hline$>30,000$ & 55 & 5.1 \\
\hline \multicolumn{3}{|l|}{ Residence } \\
\hline Urban & 515 & 47.5 \\
\hline Rural & 570 & 52.5 \\
\hline \multicolumn{3}{|l|}{ Age at First Birth } \\
\hline$<20$ & 228 & 26.9 \\
\hline $20+$ & 620 & 73.1 \\
\hline
\end{tabular}

Forty three percent of the respondents reported to have heard about contraception with a majority reporting their sources of information as friends and the mass media. The penetrating insight of the media on reproductive health is crucial to this knowledge. The knowledge of contraception is a crucial factor in usage because people who do not know a contraceptive cannot use it. While knowledge of contraception is average, usage of a particular contraceptive in the study area is poor. Only $43 \%$ of the respondents indicated to have heard and known any contraception type. This is very low compared to National figures. The National Demographic and Health Survey of Nigeria (2009) reported that knowledge of any contraceptive method is widespread with $72 \%$ of all women and $90 \%$ of all men knowing at least one method of contraception. In discussing usage, the NDHS (2009) reported that the male 
condom was the most commonly used contraception method followed by the pills. This position is sustained by this study.

Condom is the commonest contraception that respondents have knowledge of, with $23.7 \%$, while the least use is ovulation with
$7.3 \%$ and others with $4.7 \%$. The use of contraception is very high among respondents despite the high non response to the first question on knowledge. This is indicative of a poorly informed population because of the number presently using any contraception.
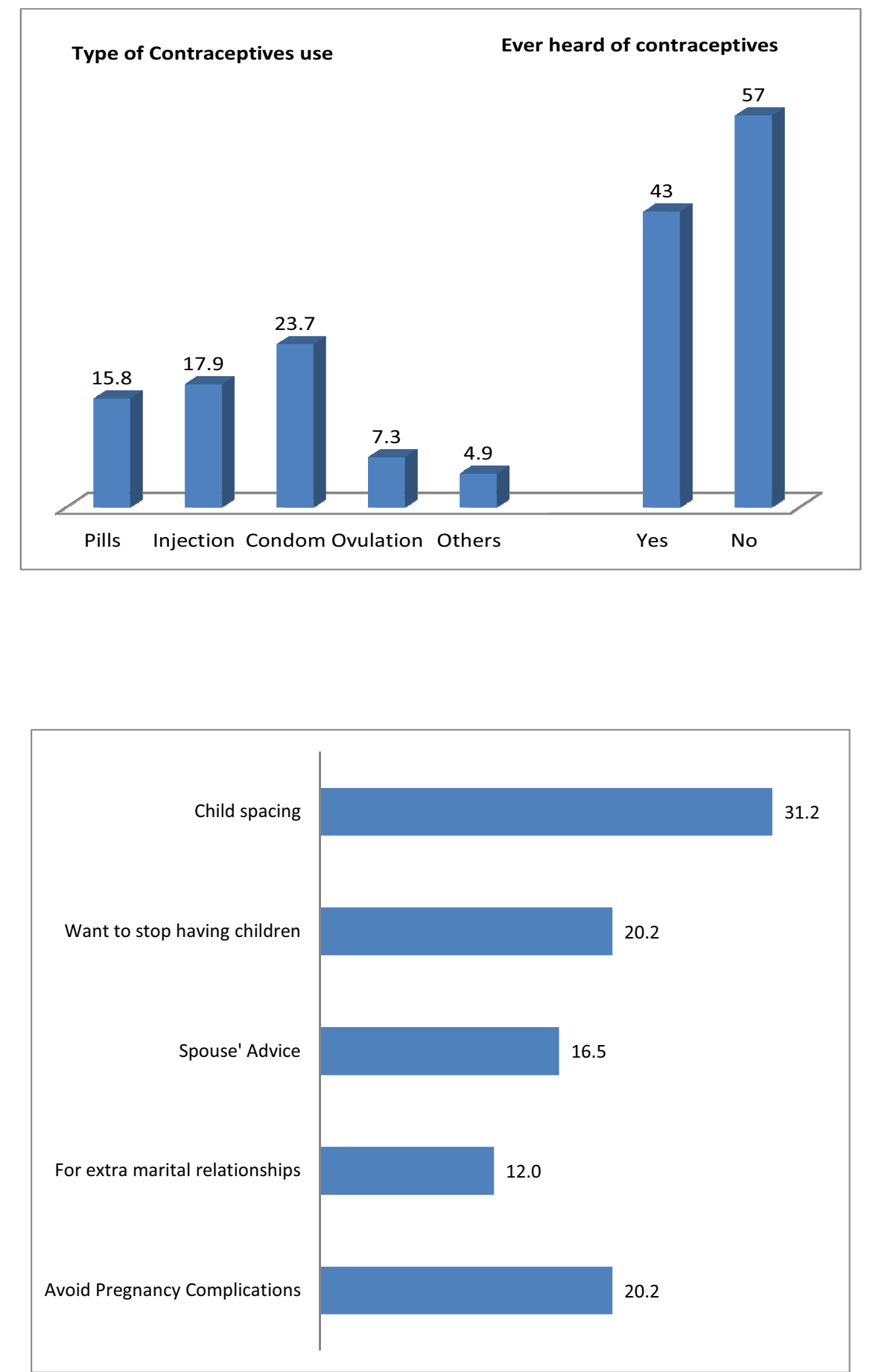

Figure 2: Reasons why respondents use contraceptives

Expanding the number of family planning options available to women is a critical part of increasing contraceptive coverage, decreasing unintended pregnancies and reducing maternal morbidity and mortality around the globe
(Baveja et al., 2000; Bongaarts \& Johansson, 2002).

Table 2 indicates that married and cohabiting women are the category with the highest number and percentage of use of contraceptive. 
This category has $45.5 \%$ of ever using any contraception. The DSW are the next in usage with $50.0 \%$. The singles are the least of those who use contraception. Contraceptive use is highest among those between 2I-34 years. This age group is the most sexually active by virtue of their age as young people for the married or those entering the sexually active age. Those less than 20 years are the least in the use of contraceptive with $42.2 \%$. This is a sign that often they are outside marriage and engaged in sexual activity for fun. There is a significant relationship between age and use of contraception.

Table 2 Distribution of respondents by socio-demographic characteristics and contraceptive use

\begin{tabular}{|c|c|c|}
\hline Selected background variables & $\begin{array}{l}\text { Ever used contraceptives } \\
(N=514)\end{array}$ & Total \\
\hline \multicolumn{3}{|l|}{ Marital status } \\
\hline Single & 39.8 & 261 \\
\hline Married/Cohabiting & 50.0 & 742 \\
\hline *DSW & 47.6 & 82 \\
\hline \multicolumn{3}{|l|}{ Age group } \\
\hline $15-19$ & 42.2 & 85 \\
\hline $20-24$ & 40.4 & 203 \\
\hline $25-29$ & 52.6 & 266 \\
\hline $30-34$ & 49.3 & 213 \\
\hline $35-39$ & 53.1 & 147 \\
\hline $40-44$ & 37.1 & 116 \\
\hline $45-49$ & 54.5 & 55 \\
\hline \multicolumn{3}{|l|}{ Religion } \\
\hline Catholic & 48.0 & 811 \\
\hline Protestant & 45.7 & 243 \\
\hline Muslim & 52.2 & 23 \\
\hline Traditional & 25.0 & 8 \\
\hline \multicolumn{3}{|l|}{ Education } \\
\hline Never attended school & 36.1 & 72 \\
\hline Primary & 37.7 & 146 \\
\hline Secondary & 56.1 & 410 \\
\hline Post-secondary & 44.4 & 457 \\
\hline \multicolumn{3}{|l|}{ Currently employed } \\
\hline Yes & 57.6 & 629 \\
\hline No & 33.6 & 432 \\
\hline \multicolumn{3}{|l|}{ Residence } \\
\hline Urban & 52.8 & 515 \\
\hline Rural & 42.5 & 570 \\
\hline \multicolumn{3}{|l|}{ Age at first birth } \\
\hline$<20$ & 61.0 & 228 \\
\hline $20>$ & 49.5 & 620 \\
\hline
\end{tabular}

*Divorced, separated and widowed were merged

Protestants are the highest religious category that uses contraception with over $45.7 \%$. The Traditionalists are least category that uses contraception. This is obvious as these are often uninformed about them.
More respondents who are had at least secondary school education use contraception. The results show that those with secondary education have $56.1 \%$ contraception use compared with $36.1 \%$ for those who never attended 
school. The change agent maxim mention earlier is brought to bear here, that is, those with higher education are more likely to use contraception because of their information and exposure. Respondents who were employed $(57.3 \%)$ use more contraception than those not in any paid employment $(33.6 \%)$. The urban residents (52.8) use contraception more than those in the rural areas (42.8\%). Child spacing (3I.25) appeared to the most cited reason for using contraceptives among respondents while the desire to stop having children and to avoid pregnancy-related complications each had $20.2 \%$ (Figure 2).

The multivariate analysis was carried out to find out the likelihood of contraception use using all the variables in the bivariate analysis. Table 2 indicates that the likelihood of contraception use is higher among those who are age 35 years and above. This is because the odd ratio shows that this category is 1.189 times likely to use condom than those within the reference category (those less than 20 years). Though respondents within the age bracket $2 \mathrm{I}$ 34 show a statistically significant relationship with contraceptive use yet the likelihood of contraceptive use is .690 times less likely among the same category than the reference category $(<20)$.

Table 3 Likelihood of using contraceptives

\begin{tabular}{|c|c|}
\hline Selected variables & Odds ratio \\
\hline \multicolumn{2}{|l|}{ Age } \\
\hline$<20$ (ref) & 1.00 \\
\hline $21-34$ & $.690 *$ \\
\hline $35>$ & 1.189 \\
\hline \multicolumn{2}{|l|}{ Marital status } \\
\hline Single(ref) & 1.00 \\
\hline Married & $0.606 *$ \\
\hline DSW & 2.404 \\
\hline \multicolumn{2}{|l|}{ Religion } \\
\hline Catholic(ref) & 1.00 \\
\hline Protestant & $1.009 *$ \\
\hline Muslim & .552 \\
\hline Traditional & .450 \\
\hline \multicolumn{2}{|l|}{ Education } \\
\hline No school(ref) & 1.00 \\
\hline Primary & .673 \\
\hline Secondary & $.892 *$ \\
\hline Tertiary & $.608^{*}$ \\
\hline \multicolumn{2}{|l|}{ Currently employed } \\
\hline Yes(ref) & 1.00 \\
\hline No & $.446 *$ \\
\hline \multicolumn{2}{|l|}{ Residence } \\
\hline Urban(ref) & 1.00 \\
\hline Rural & $.95 I^{*}$ \\
\hline
\end{tabular}

Table 3 also shows that married people are less likely to use contraceptives while those who are widowed, divorced or separated are more likely to use contraception. Though the married category showed a statistically significant relation- ship with contraception use yet the likelihood of contraception use is least among this category. The DSW are the most likely category to use contraception. Protestants are more than once likely to use contraception with the others 
(Muslim, Traditionalist) are not likely to use contraception. Those who have some education are all more likely to use contraception than those with no form of schooling. Those who are employed are more likely to use contraception because the reference category which equals one is higher than those not employed. The urban residents are also more likely to using contraceptives.

\section{Discussion}

The results of this study indicate that knowledge of contraception is average in both rural and urban centres of the study area. This is especially true compared with national figures as shown in the NDHS (2009) that over $80 \%$ among women and $90 \%$ of male respondents have knowledge of contraception. This awareness is lower in Nigeria than it is in other developing countries including Mexico, Kenya, India and South Africa (Ellertson et al., 200I; Muia, 1999; Takkar et al., 2005; Larger et al., 1999).

The study also showed that condom was the commonest modern contraception that respondents reported as known and use, followed by pills. This corroborates the findings of Ozumba et al. 2005) who found that condom followed by oral pills were the most popular contraceptive methods used because they can easily be procured over the counter. Presently DSW women were the most likely to use contraception in the study and this finding is in line with the findings of Gilda etal. (2006), they found that DSW women are more likely to use any contraceptive. Women who are in their twenties are the most likely to have used a contraceptive.

The Protestants are most likely to use contraception. This finding contradicts those of Gilda etal, (2006) who found that "compared with Catholics, Muslim and other Christian had odds of having had an unwanted pregnancy as a result of non use of contraception. Education of respondents also played a very significant function in the knowledge and utilization of contraception. This has been consistently stated as a function of use of contraception as it shows that women with secondary education and above are more likely to use contraception as a result of information they have on it (contraception).

Contraceptive awareness was more among the urban than rural respondent (Ozumba etal 2006). Some respondents reported to have used contraceptives that they have heard about. This is a common trend because people are more likely to use the method they are familiar with and not otherwise. The multivariate analysis showed that the likelihood of using contraception was higher among older women 34 years and above (Odds I.189), DSW (2.404), Protestants (1.009), Catholics (I.00), Employed ( 1.00$)$, urban residents $(1.00)$ and all those who have heard and use different contraceptives. This study has some limitation. For instance, the survey is relatively small conducted in one part of Nigeria, the result require further investigation in other parts of Nigeria. It was also a community based survey and the people do not have knowledge of contraception as shown by results. Hence uptake of contraception may be lower here than other parts of the country.

\section{Conclusion}

This study was undertaken to assess the relationship between knowledge about contraception and its use among women. To do this, study objectives were drawn including assessing women's knowledge, contraception they know, background characteristics and effect on contraception. In executing the study, it was found that women's knowledge of contraception was below National figures. It was also found that socio demographic characteristics played very dominant role in determining the knowledge and use of contraception. For instance, education was found to be very crucial in determining knowledge and utilization of contraception. Location was also found to be important as residents of urban areas had more information hence more knowledgeable about contraception and these results in higher usage than in the rural areas. These findings are in line with several studies hence urgent and concerted effort is therefore needed to improve women knowledge base to facilitate the actualization of the much talked about population control through family planning.

Given the importance of family planning to the reduction of growing population, it is crucial to embark on an aggressive education and enlightenment of the people on the need to use contraception in order to prevent unwanted, 
unintended and ill-timed pregnancies. The media should be effectively harnessed to take its rightful position in the dissemination of information to the people. Service intentions are therefore necessary so that women know the different methods, where to get it, and the appropriate time interval for its use.

\section{References}

Bankole, A., Sedgh, G. Okonofua, F., Imarhiagbe,C., Hussain, R.\& Wulf, D 2009. Barriers to Safe Motherhood in Nigeria; New York: Guttmacher Institute.

Ellertson, C., Winikoff, B., Armstrong, E., Camp, S. and Senanayake, P. 1995. Expanding access to emergency contraception in developing countries. Stud Fam Plann, 26:25I-263.

Filmer, D. and Pritchett, L.H. 200 I Estimating wealth effects without expenditure data - or tears: an application to educational enrollments in states of India, Demography, 38(I): I I5-132.

Gilda, S., Akinrinola B., Oye-Adeniran, B, Adewole, I., Susheela, S. and Rubina, H. 2006 Unwanted Pregnancy and Associated Factors Among Nigerian Women. International Family Planning Perspectives 32(4)

Henshaw, S. K., Susheela Singh, Boniface A. OyeAdeniran, Isaac F. Adewole, Ngozi Iwere and Yvette P. Cuca 1998. The incidence of induced abortion in Nigeria, International Family Planning Perspectives, 24(4):156-164.

Hussain, R., Bankole, A., Singh, S. and Wulf, D. 2005. Reducing Unintended Pregnancy in Nigeria: Differing Contraceptive Needs. Research in Brief, No. 4. Alan Guttmacher Institute, New York;

Ladipo, O.A. 1989. Preventing and managing complications of induced abortion in Third World countries, International Journal of Gynaecology \& Obstetrics, 3 (Suppl.):2I-3I.

Landon M., R. Mlobeli , Di Cooper, J \&. Smit, Chelsea M. 2007. Knowledge and use of emergency contraception among women in the Western Cape province of South Africa: a crosssectional study. BMC Women's Health 7(I)

Langer, A, Harper, C, Garcia-Barrios, C, Schiavon, R, Heimburger, A, Elul, B, Renoso Delgado, S., Ellertson, C. Emergency Contraception in Mexico City: what do health care providers and potential users

Makinwa-Adebusoye, P., Singh, S. and Audam, S. 1997. Nigerian health professionals' perceptions about abortion practice, International Family Planning Perspectives 23(4): 155-161;
Muia, E., Ellertson, C., Lukhando, M., Elul, B., Clark, S. and Olenja, J. 1999. Emergency contraception in Nairobi, Kenya: knowledge, attitudes, and practices among policymakers, family planning providers, and clients, and university students. Contraception, 60:223-232.

National Population Commission (NPC), Federal Republic of Nigeria and ORC Macro, Nigeria Demographic and Health Survey 2003, Calverton, MD, USA: NPC and ORC Macro, 2004, p. 104.

NPC, Nigeria Demographic and Health Survey 1999, Calverton, MD, USA: National Population Commission and ORC Macro, 2000.

NPC, Nigeria Demographic and Health Survey 2009, Calverton, MD, USA: National Population Commission and ORC Macro, 2008.

Okonofua, F.E, 1994. Induced abortion: a risk factor for secondary infertility in Nigerian women, Journal of Obstetrics \& Gynaecology, 14(2):272276;

Okonofua FE Abejide, A. \& Roger A.I., 1999 Assessing the prevalence and determinants of unwanted pregnancy and induced abortion in Nigeria, Studies in Family Planning, ,30(I):67-77.

Orji, EO and Onwudiegwu U. 2002, Prevalence and determinants of contraceptive practice in a defined Nigerian population, Journal of Obstetrics \& Gynaecology, , 22(5):540-543;

Oye-Adeniran BA et al., 2004, op. cit. (see reference I); and Okonofua FE et al., 1999, op. cit. (see reference 2).

Oye-Adeniran BA et al., 2004 Community-based survey of unwanted pregnancy in southwestern Nigeria, African Journal of Reproductive Health, , 8(3): I03-II5.

Oye-Adeniran BA et al., Contraceptive prevalence among young women in Nigeria, Journal of Obstetrics \& Gynecology, 2005, 25(2): | 82-185.

Oye-Adeniran BA, Umoh AV and Nnatu SN, 2002 Complications of unsafe abortion: a case study and the need for abortion law reform in Nigeria, Reproductive Health Matters, , I0(19): I8-2I; and Adewole I, Trends in postabortal mortality and morbidity in Ibadan, Nigeria, International Journal of Gynecology \& Obstetrics, 1992, 38(I): I I 5-I I 8.

Ozumba, B.O., Obi, S., ljioma, N., 2005. Knowledge, attitude and practice of modern contraception among single women in a rural and urban community in Southeast Nigeria Journal of Obstetrics and Gynaecology, 25(3); 292 - 295

Takkar N, Goel P, Saha PK, Dua D: Contraceptive practices and awareness of emergency contraception in educated working women. Indian J Med Sci, 59: I43-9. 